\title{
Title: A new generation of emissions scenarios should cover blind spots in the carbon budget space
}

\author{
Abstract: \\ Future emissions scenarios in the IPCC sixth assessment report should be able to explore carbon \\ budget space in a systematic manner, which would be robust to the updates of latest climate science \\ and policy decisions in order to assess policy implications.
}

The impacts of one degree of global warming are currently being experienced around the globe ${ }^{1}$. For some regions, communities, or ecosystems, these impacts are already devastating. Together with the certainty that unchecked climate change will bring much worse impacts, climate action is coming to the forefront of societal debate, be it through youth climate strikes, business initiatives, or government action. Understanding the requirements for keeping warming within acceptable limits has thus become essential. The state of scientific knowledge in this area has recently been assessed in the Special Report on Global Warming of $1.5^{\circ} \mathrm{C}$ (SR1.5) by the Intergovernmental Panel on Climate Change (IPCC) ${ }^{2}$. Besides an assessment of the amount of carbon-dioxide that can still be emitted while keeping warming to $1.5^{\circ} \mathrm{C}$ relative to preindustrial levels (so-called carbon budgets), the report also describes pathways with long-term societal transformations that would be consistent with keeping to these carbon budgets. These pathways are explored by Integrated Assessment Models (IAMs) and the modelled transformations of the energy and land-use system depend critically on the assumed available carbon budgets. Carbon budget estimates come with an uncertainty range and their values are updated over time as scientific knowledge progresses ${ }^{3}$. Consequently, updated ex-post assessments of IAM scenarios can thus results in projected temperature outcomes that differ from the climate targets which were originally designed for. This is a situation that is bound to repeat itself in the future as long as scenario modelling focuses on generating scenarios consistent with one specific or a limited set of carbon budgets. This can be avoided, however, by designing the next generation of IAM scenarios produced by the larger community in an appropriate way. We here suggest a community scenario effort that may help to systematically respond to the issue, and allow IAM scenarios to inform global climate policy based on the most recent climate science at any time.

The SR1.5 assessed emissions scenarios from the published literature that were created with exante carbon budgets assumptions intended to be consistent with certain climate outcomes. Specifically, major model inter-comparison studies such as ADVANCE ${ }^{4}$, CD-LINKS ${ }^{5}$ and EMF33 ${ }^{6}$ contributed substantially to the SR1.5 database ${ }^{7}$ with a large number of scenarios. These studies focused on three levels of cumulative emissions of carbon dioxide from 2011 to 2100 (400, 1000 and $1600 \mathrm{GtCO}_{2}$ ) and contributed a large number of scenarios with these specific characteristics to the literature (Fig. 1a). Based on the climate assessment of the IPCC Fifth Assessment (AR5) these budgets corresponded to 
limiting temperature change in 2100 below $1.5^{\circ} \mathrm{C}$ with a $50 \%$ chance, and below $2^{\circ} \mathrm{C}$ with a $66 \%$ and $50 \%$ chance, respectively ${ }^{8}$.

However, the emphasis on a limited set of carbon budgets is problematic since carbon budget estimates are expected to be refined and improved as time passes, and any limited set of carbon budgets will thus continuously run the risk of being outdated by the time that they are assessed as part of larger climate science assessments by the IPCC that take place every 6 to 7 years. This is of particular importance because even small revisions of carbon budget estimates can have big implications for associated insights from transformation pathways for stringent climate goals like limiting warming to $1.5^{\circ} \mathrm{C}$, because the absence of significant global greenhouse gas emissions reductions to date have resulted in a very small remaining carbon budget. For example, a 200 to $300 \mathrm{GtCO}_{2}$ update in the remaining carbon budget estimate (as was the case between $\mathrm{AR5}^{9}$ and SR1.5²) strongly affects the perception of the mitigation challenge - with major differences in modelled carbon prices which is exhibited in Figure 2 (e.g. 250US\$/tCO 2 differences from 600 to $800 \mathrm{GtCO}_{2}$ in cumulative emissions) and different conclusions about the feasibility of the long-term temperature goal of the UN Paris Agreement both in academic and climate policy circles.

Different aspects contribute to the current uncertainty surrounding carbon budget estimates and are discussed in detail elsewhere ${ }^{23}$. These uncertainties won't be resolved entirely at any point in the near future, and continued improvements of these estimates should hence be anticipated as time, climate change, and our understanding of the physics of the climate change problem progresses. IAM scenario modelling exercises need to prepare for this certain evolution, and this poses a clear scientific challenge for the energy system and scenario modelling community. The traditional approach that has been followed by the community, which consists of pre-selecting a limited set of budgets, runs the risk of missing the mark and is likely to result in a situation where the majority of IAM scenarios do not match specific levels of global warming or temperature targets that are considered relevant to climate policy ${ }^{10}$.

We thus propose a new approach that could be followed by the scenario modelling community and which explores the carbon budget space in a more systematic manner in line with single-model studies published earlier ${ }^{11,12}$. This new approach permits to hedge against future budget uncertainties by not putting all eggs into one so-called 'carbon budget basket'. We propose to explore 14 scenarios associated with remaining carbon budgets from $200 \mathrm{GtCO}_{2}$ to $2000 \mathrm{GtCO}_{2}$ starting from 2018 and counting until scenarios reach global net zero $\mathrm{CO}_{2}$ emissions. The domain between 200 and 1000 $\mathrm{GtCO}_{2}$ would be covered in $100 \mathrm{GtCO}_{2}$ increments to explore the space that could be considered consistent with limiting warming well-below $2^{\circ} \mathrm{C}$ in detail; the domain between 1000 and $2000 \mathrm{GtCO}_{2}$ would be covered with $200 \mathrm{GtCO}_{2}$ increments to cover possible higher carbon budgets that are currently assessed to result in a low chance of limiting warming to well-below $2^{\circ} \mathrm{C}$. In case a model was unable to create a scenario for a specific small carbon budget, this information would also be 
reported.

The benefits of the systematic exploration of the carbon budget in this scenario set are obvious. The risks that scenarios do not map to specific climate targets due to changes in carbon budgets or other issues related to the Earth-system response to greenhouse gases can be avoided. For instance, recent literature suggests that climate feedbacks have been underestimated in the past ${ }^{13}, 14$, and non$\mathrm{CO}_{2}$ contributions to mitigation pathways have been notoriously uncertain. Non- $\mathrm{CO}_{2}$ emissions abatement potential and associated costs differ widely across IAMs ${ }^{15}$. This has traditionally led to strong variations in carbon budgets across models, even when aiming for a similar climate outcome ${ }^{16}$. Our proposed scenario framework provides the advantage that temperature consequences of different $\mathrm{CO}_{2}$ and non- $\mathrm{CO}_{2}$ relationships can be assessed systematically across models. In other words, for assessing a certain temperature level, one may rely on different carbon budget runs from different models, depending on the respective non- $\mathrm{CO}_{2}$ emissions fingerprint of each respective model. At the same time, it would also improve the understanding of socio-economic uncertainties surrounding the climate outcome of a given $\mathrm{CO}_{2}$ budget as a result of the variation in associated non- $\mathrm{CO}_{2}$ emissions. We also propose to apply carbon budgets until the time of global $\mathrm{CO}_{2}$ emissions becoming net zero, which differs from the usual IAM approach that applies carbon budgets until the end of the century. The use of such a peak carbon budget makes peak warming and overshoot of a specific temperature target an explicit design choice, in line with insights of the IPCC SR1.5².

A final question that the scenario design could help to address is the consistency of long-term carbon budgets with currently proposed near-term policies, such as the nationally determined contributions (NDC) under the UN Paris Agreement. To this purpose, we suggest to have the same carbon budgets scenarios but with different assumptions for near-term policies. For example, for each proposed long-term budget, one could run one scenario assuming the implementation of the NDCs, and another scenario assuming immediate action consistent with the overall carbon budget. Contrasting the two scenarios will help to understand whether the NDCs are consistent with a specific peak carbon budget, and would in addition help to understand in which areas further acceleration of actions beyond the NDC would be necessary. This would provide critical information for the Global Stocktake process that will be conducted as part of the implementation of the UN Paris Agreement.

We think that the proposed scenarios can assure consistency between the physical climate science and mitigation assessments across the different parts of the climate change research community, and can therefore be critical for the integration of work across the different Working Groups of the IPCC when they prepare their Sixth Assessment Report (AR6) over the coming years. Time, however, is running short, and publication deadlines for studies to be included in the AR6 are approaching quickly. At the latest by early summer in 2020, any new scenario runs should be ready and available for inclusion in the assessment, accompanied by a peer-reviewed publication in a scientific journal. Given the importance of ensuring that the latest insights in climate science are adequately reflected in 
assessments of climate change mitigation, we thus call upon the community to dedicate some time to this important new effort.

a)

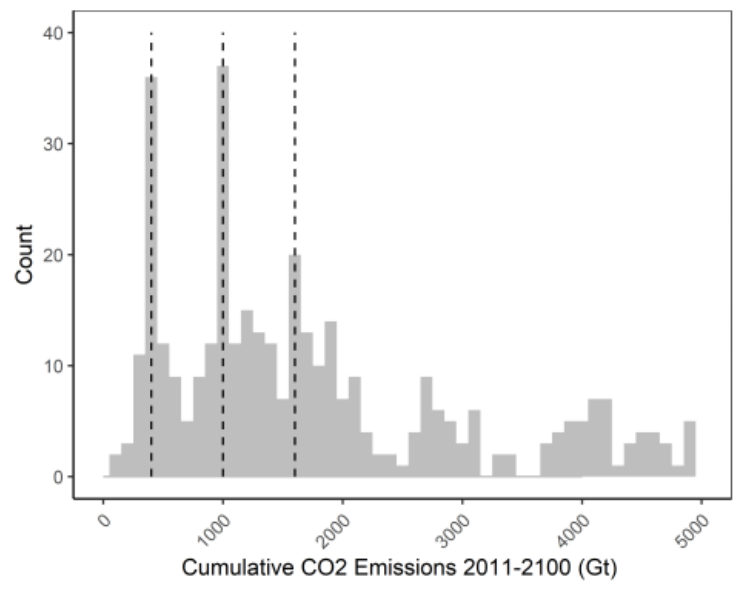

b)

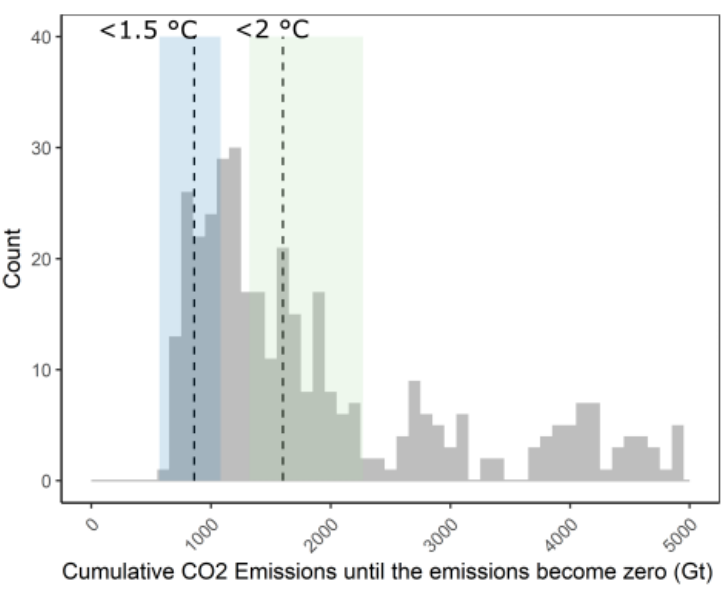

Figure 1 Frequency distribution of IAM scenarios by (a) cumulative carbon emissions from 2011 to 2100 and (b) cumulative carbon emissions until the emissions become zero ${ }^{7}$. The blue and green ranges in panel (b) represent 1.5 and $2{ }^{\circ} \mathrm{C}$ warming from $33^{\text {th }}$ to $67^{\text {th }}$ percentiles of TCRE. The dashed lines in panel (b) are median estimates of 1.5 and $2{ }^{\circ} \mathrm{C}$ warming of TCRE. 


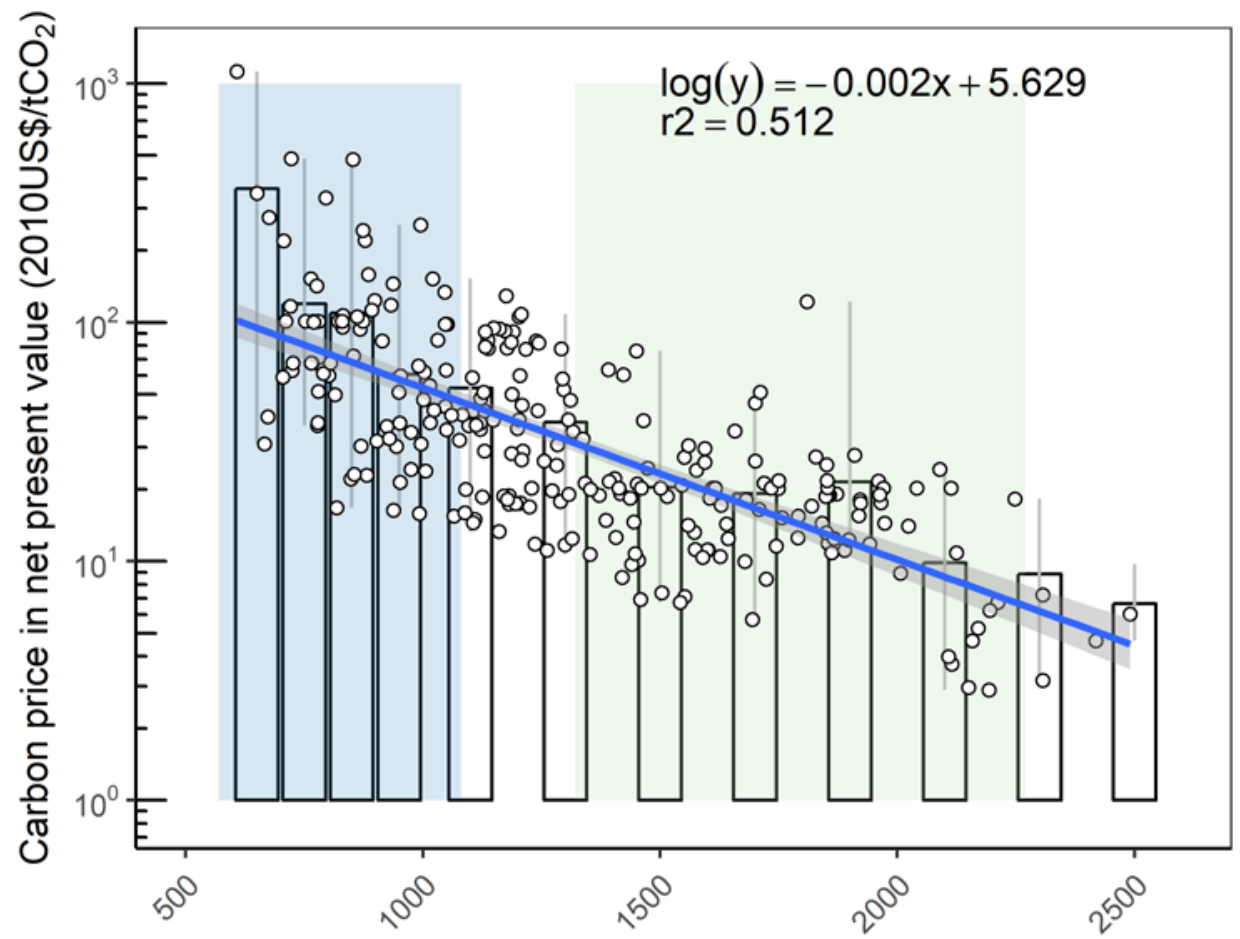

Cumulative $\mathrm{CO}_{2}$ emissions until the emissions become zero (Gt)

Figure 2 Carbon price and cumulative carbon emissions. Carbon price in y axis is represented by net present value (discount rate is $\mathbf{5 \%}$ ) The bars are the carbon price average for each cumulative emissions levels, and 100 and $200 \mathrm{GtCO}_{2}$ steps are taken for 600-1000 and 100-2500 $\mathrm{GtCO}_{2}$, respectively. The error bar shows the range of carbon prices for each bar. The log-linear regression results are shown as a line and confidential interval is represented as grey range. The blue and green ranges represent 1.5 and $2{ }^{\circ} \mathrm{C}$ warming from $33^{\text {th }}$ to $67^{\text {th }}$ percentiles of TCRE.

References

1. Intergovernmental Panel on Climate Change, (IPCC). Global Warming of $1.5^{\circ}$ C: An IPCC Special Report on the Impacts of Global Warming of $1.5^{\circ} \mathrm{C}$ Above Pre-industrial Levels and Related Global Greenhouse Gas Emission Pathways, in the Context of Strengthening the Global Response to the Threat of Climate Change, Sustainable Development, and Efforts to Eradicate Poverty. Intergovernmental Panel on Climate Change, 2018.

2. Rogelj J, Shindell D, Jiang K, Fifita S, Forster P, Ginzburg V, et al. Mitigation pathways compatible with $1.5^{\circ} \mathrm{C}$ in the context of sustainable development. Special Report on the impacts of global warming of $1.5^{\circ} \mathrm{C}$. Intergovernmental Panel on Climate Change: Geneva, 2018. 
3. Rogelj J, Forster PM, Kriegler E, Smith CJ, Séférian R. Estimating and tracking the remaining carbon budget for stringent climate targets. Nature 2019, 571(7765): 335-342.

4. Luderer G, Vrontisi Z, Bertram C, Edelenbosch OY, Pietzcker RC, Rogelj J, et al. Residual fossil CO2 emissions in $1.5-2{ }^{\circ} \mathrm{C}$ pathways. Nature Climate Change 2018.

5. McCollum DL, Zhou W, Bertram C, de Boer H-S, Bosetti V, Busch S, et al. Energy investment needs for fulfilling the Paris Agreement and achieving the Sustainable Development Goals. Nature Energy 2018.

6. Bauer N, Rose SK, Fujimori S, van Vuuren DP, Weyant J, Wise M, et al. Global energy sector emission reductions and bioenergy use: overview of the bioenergy demand phase of the EMF-33 model comparison. Climatic Change 2018.

7. Huppmann D, Kriegler E, Krey V, Riahi K, Rogelj J, Rose SK, et al. IAMC $1.5^{\circ} \mathrm{C}$ Scenario Explorer and Data hosted by IIASA. Integrated Assessment Modeling Consortium \& International Institute for Applied Systems Analysis; 2018.

8. Rogelj J, Luderer G, Pietzcker RC, Kriegler E, Schaeffer M, Krey V, et al. Energy system transformations for limiting end-of-century warming to below $1.5^{\circ} \mathrm{C}$. Nature Clim Change 2015, 5(6): 519-527.

9. Clarke L, Jiang K, Akimoto K, Babiker M, Blanford G, Fisher-Vanden K, et al. Assessing Transformation Pathways. In: Edenhofer O, Pichs-Madruga R, Sokona Y, Farahani E, Kadner S, Seyboth K, et al. (eds). Climate Change 2014: Mitigation of Climate Change. Contribution of Working Group III to the Fifth Assessment Report of the Intergovernmental Panel on Climate Change. Cambridge University Press: Cambridge, United Kingdom and New York, NY, USA, 2014, pp 413-510.

10. Schleussner C-F, Rogelj J, Schaeffer M, Lissner T, Licker R, Fischer EM, et al. Science and policy characteristics of the Paris Agreement temperature goal. Nature Climate Change 2016, 6: 827.

11. Rogelj J, McCollum DL, Reisinger A, Meinshausen M, Riahi K. Probabilistic cost estimates for climate change mitigation. Nature 2013, 493: 79.

12. Luderer G, Pietzcker RC, Bertram C, Kriegler E, Meinshausen M, Edenhofer O. Economic 
mitigation challenges: how further delay closes the door for achieving climate targets. Environmental Research Letters 2013, 8(3): 034033.

13. Lowe JA, Bernie D. The impact of Earth system feedbacks on carbon budgets and climate response. Philosophical Transactions of the Royal Society A: Mathematical, Physical and Engineering Sciences 2018, 376(2119).

14. Gasser T, Kechiar M, Ciais P, Burke EJ, Kleinen T, Zhu D, et al. Path-dependent reductions in CO2 emission budgets caused by permafrost carbon release. Nature Geoscience 2018, 11(11): 830-835.

15. Gernaat DEHJ, Calvin K, Lucas PL, Luderer G, Otto SAC, Rao S, et al. Understanding the contribution of non-carbon dioxide gases in deep mitigation scenarios. Global Environmental Change 2015, 33(0): 142-153.

16. Rogelj J, Popp A, Calvin KV, Luderer G, Emmerling J, Gernaat D, et al. Scenarios towards limiting global mean temperature increase below $1.5^{\circ} \mathrm{C}$. Nature Climate Change 2018. 